\title{
Care for Incarcerated Patients Hospitalized with COVID-19
}

\author{
Alan P. Jacobsen, M.B., B.Ch., B.A.O. ' (D), Talia Robledo-Gil, M.D. ', \\ Jordan H. Nahas-Vigon, M.D. ' , Jeremy A. Epstein, M.D. ${ }^{7}$, Zackary D. Berger, M.D., Ph.D. ' , \\ and Carolyn B. Sufrin, M.D., Ph.D.2
}

'Department of Medicine, Johns Hopkins University School of Medicine, Baltimore, MD, USA; ${ }^{2}$ Department of Gynecology and Obstetrics, Johns Hopkins University School of Medicine, Baltimore, MD, USA.

The COVID-19 pandemic has reshaped health care delivery for all patients but has distinctly affected the most marginalized people in society. Incarcerated patients are both more likely to be infected and more likely to die from COVID-19. There is a paucity of guidance for the care of incarcerated patients hospitalized with COVID-19. This article will discuss how patient privacy, adequate communication, and advance care planning are rights that incarcerated patients may not experience during this pandemic. We highlight the role of compassionate release and note how COVID-19 may affect this prospect. A number of pragmatic recommendations are made to attenuate the discrepancy in hospital care experienced by those admitted from prisons and jails. Physicians must be familiar with the relevant hospital policies, be prepared to adapt their practices in order to overcome barriers to care, such as continuous shackling, and advocate to change these policies when they conflict with patient care. Stigma, isolation, and concerns over staff safety are shared experiences for COVID-19 and incarcerated patients, but incarcerated patients have been experiencing this treatment long before the current pandemic. It is crucial that the internist demand the equitable care that we seek for all our patients.

J Gen Intern Med 36(7):2094-9

DOI: $10.1007 /$ s11606-021-06861-y

(C) Society of General Internal Medicine 2021

Clinical Vignette. A 73-year-old man with a history of heart failure, diabetes mellitus, and chronic kidney disease was admitted to hospital from a nearby prison with fevers, dyspnea, and a positive SARS-CoV-2 nasopharyngeal swab. He was transferred to a COVID-19-specific unit where he received medical care while shackled supine to his bed, with two custody officers stationed outside his room.

The clinical team did not engage in frequent conversation with the patient because of COVID restrictions. When these masked clinicians did see the patient, they were accompanied by the custody officers and failed to clearly specify their roles. He was provided food without utensils and had to use the bedpan while remaining shackled at all times. A week into the

Received November 18, 2020

Accepted April 26, 2021

Published online May 5, 2021 admission, he developed respiratory failure and was transferred to the intensive care unit where he was intubated, sedated, and remained shackled. Despite his poor prognosis, the medical team did not initiate compassionate release. Non-experimental treatment options were limited and he was not recruited into any of the COVID-19 clinical trials ongoing at the institution.

The medical team did not attempt to contact the patient's family. With worsening hypoxia and renal failure, the intensive care team requested authorization from the prison warden to contact the patient's wife and clarify goals of care. Eventually, they communicated with her and she made it clear that that the patient would never have wanted dialysis or intubation. He died in the hospital, still incarcerated.

\section{INTRODUCTION}

The COVID-19 pandemic has reshaped health care delivery for all patients but has distinctly affected the most marginalized people in society. ${ }^{1}$ Those who are incarcerated are at particularly high risk of being infected with SARS-CoV-2 due to overcrowding, inability to safely physically distance, ${ }^{2}$ sanitation issues, and the daily flow of workers through facilities. ${ }^{3-5}$ The rate of COVID-19 amongst the carceral population has been reported to be 3-14 times that of the general population of the USA. ${ }^{6,7}$ The adjusted death rate for COVID19 in the prison population is three times higher than would be expected if the age and sex distributions of the US and prison populations were equal. ${ }^{8-11}$ Amongst persons who are incarcerated, Black individuals are 3.46 times as likely to be infected as white individuals, underlining how Black people are disproportionally affected by COVID-19-and by mass incarceration - due to the effects of systemic racism. ${ }^{12,13}$

In general, jails are locally operated facilities which hold people awaiting trial, sentencing, or are sentenced to a term of less than one year. Prisons are longer term facilities run by the state or federal government which hold people serving sentences for convicted crimes lasting more than a year. ${ }^{14}$ There is significant variation in the healthcare resources available at these facilities and as a result, incarcerated patients may be transported to their local emergency department and hospitalized for a wide range of indications. ${ }^{15}$ Some policy efforts have advocated for de-population of prisons and jails, and elimination of mandatory immigration detention to mitigate the spread of COVID-19. ${ }^{3,16-20}$ However, these early release 
policies often fail to reach the most vulnerable. For example, by excluding offenses associated with lengthier sentences, elderly individuals who are incarcerated under such terms remain at risk. Ultimately, large facility outbreaks involving people at higher risk of severe COVID-19 illness - an aging prison population with a high burden of underlying chronic disease - may result in many more incarcerated patients being hospitalized. $^{21-23}$

Caring for incarcerated patients in the hospital can be difficult given security procedures such as continuous shackling of patients, hospital policies unfamiliar to residents and physicians, and structural power issues between patients, clinicians, and security personnel that impair communication and privacy. ${ }^{24,25}$ The stigma associated with COVID-19, which is based on uncertainty and fear, is similar to the stigma incarcerated patients may experience with any hospitalization, especially when healthcare staff are not familiar with caring for incarcerated patients. A number of organizations and societies have commented on the care of incarcerated patients with COVID19 , though much of it is not applicable to patients actually hospitalized (Table 1). This piecemeal guidance falls short of a comprehensive standard of care for incarcerated patients when they are at their sickest. The Amend Group at the University of California, San Francisco has developed a guide for community physicians specific to the care of incarcerated patients

Table 1 Limited Resources Provided by Major Societies and Organizations Pertaining to the Care of Incarcerated Patients Hospitalized with COVID-19

\begin{tabular}{l}
\hline \hline Source \\
\hline National Commission on \\
Correctional Health Care \\
(NCCHC)
\end{tabular}

The National Academies of Sciences, Engineering and Medicine

The Centers for Disease Control and Prevention (CDC)

Infectious Diseases Society of America (IDSA)

American College of Physicians (ACP)

American College for Emergency Physicians (ACEP)

Society of General Internal Medicine (SGIM)

Amend Group at University of California San Francisco

\section{Guidance provided}

Operational and clinical standards of care for health care delivery and management of chronic and acute medical and mental health conditions in carceral settings ${ }^{27}$ Consensus report on the best practices for implementing decarceration as a strategy to mitigate the spread of COVID-19 in prisons and jails ${ }^{19}$

General guidance focused on prevention, infection control, and the management of cases in prisons and jails ${ }^{28}$

Statement urging a strong federal and state response to assist in the prevention of Covid-19 and support access to diagnostic and management supplies in these settings Highlighted the importance of protecting prison and jails staff to mitigate the pandemic's effect on incarcerated persons and surrounding communities ${ }^{30}$ Guidance pertaining to the transfer of patients to the emergency department ${ }^{31}$

Statement which highlights disparities in outcomes between different populations affected by COVID-19 including those incarcerated $^{32}$

Guidance specific to the care for patients hospitalized from the carceral setting with COVID-19 $19^{26}$ hospitalized with COVID-19 where they highlight the importance of advance care planning, surrogate decision makers, and communication with prison and jail staff. ${ }^{26} \mathrm{We}$ will review some of the intricacies in caring for these vulnerable patients who are subject to the stigma of both being incarcerated and being diagnosed with COVID-19, provide some practical recommendations, and ultimately hope to inspire internists to advocate for more humane treatment of incarcerated patients hospitalized with COVID-19.

\section{PATIENT PRIVACY, CONFIDENTIALITY, AND THE IMPACT OF "SECURITY" POLICIES}

The principles of privacy and confidentiality, in theory, apply to all patients, including those hospitalized from prisons and jails. Unfortunately, competing interests in the form of the safety of healthcare staff and the public as a whole may undermine this principle. Similarly, caring for all patients with COVID-19 in a single unit, while clearly practical, subjugates the principle of privacy. The National Commission on Correctional Health Care (NCCHC) ${ }^{27}$ Standard A-07 Privacy of Care states that "health care encounters and exchanges of information are to remain in private," unless there are "extenuating circumstances. ${ }^{27}$ The Health Insurance Portability and Accountability Act (HIPAA) should equally apply to incarcerated individuals; however, protected health information (PHI) may be disclosed to a prison or jail staff, if deemed that such PHI is necessary for the provision of healthcare or safety of the patient, or other individuals in the facility. ${ }^{33}$

Hospital security policies may also contravene this principle of confidentiality. The policy at many institutions including our own requires that officers be permitted to remain with the patient in custody at all times, and although it is suggested that conversations be conducted out of hearing range, the officers must be allowed to remain within direct sight of the patient. ${ }^{34,35}$ Similarly, this policy requires that the patient should not be released for bathroom use, and instead use a urinal or bedpan while they remain shackled to a stationary object at all time. $^{34}$

The purported benefits of these policies for healthcare staff safety are not supported by evidence and may have a deleterious effect on the care of the incarcerated patient. ${ }^{36}$ For example, continuous shackling that limits mobility will cause deconditioning, ${ }^{37}$ prevent the patient's ability to self-prone, and hinder the management of a cardiac arrest-already a predicament in a patient with COVID-19. ${ }^{38}$ The presence of security officers in the room also has implications for infection control. At a time when family members are restricted from seeing their dying loved ones, and PPE is limited, it is counterintuitive to be supplying extra PPE and risking further COVID-19 exposure. Our hospital policy recommends that security officers follow our institutional infection control standards and procedures regarding isolation. Finally, continuously shackling a patient suffering from post-intensive care 
syndrome severely limits the use of physical therapy - a core component of care for these patients. ${ }^{39}$

Internists should review their hospitals' policies surrounding the care of incarcerated patients, to ensure a clear understanding of what is expected from a security perspective, work within these limits to care for their patients with dignity and respect, and change these policies when they conflict with patient care. A simple practical step to increase patient privacy is to request that security officers wear headphones for the duration of a clinical discussion if they are unable to move out of hearing range. We disagree with the practice of shackling all patients, at all times, particularly when they are physically incapacitated by illness or when security staff has not identified a legitimate public safety risk. We suggest that exceptions be built into these policies when circumstances dictate, for example when a patient is intubated or requires prone positioning. Such a practice would not be without precedent as 32 states now have laws which prohibit shackling of women during pregnancy, labor, and delivery, and post-partum recovery. ${ }^{40}$

\section{COMMUNICATION}

Each morning we find ourselves shouting through personal protective equipment (PPE) from the doorway as we try to allay fears and manage expectations in patients affected by COVID-19. Prisons and jails ask internists to limit communication with family and refrain from informing patients about post-discharge follow-up appointments due to the theoretical concern that this could facilitate family assistance in staging an escape. ${ }^{41}$ No legislation, regulations, or guidelines exist to consult regarding this practice. This inability to explain care plans with patients and families may foster mistrust of healthcare providers. The use of masks or personal respirators, combined with this "secrecy," and perhaps lower health literacy in some patients, ${ }^{42}$ can result in grossly inadequate communication between physicians and their incarcerated patients. Physicians caring for patients from prisons and jails should be aware of the few conventional standards that exist, such as not disclosing the location and timing of tests, procedures, and follow-up appointments. Aside from these informal standards, we encourage physicians to fully explain the patient's diagnosis, treatment, prognosis, and follow-up plan without worry of security breaches.

\section{ADVANCED CARE PLANNING AND SURROGATE DECISION MAKING}

Given the risk of mortality among patients admitted with COVID-19, physicians should confirm advanced care planning (ACP) on admission and initiate goals of care discussions early with all patients. Despite a population which is aging, with a higher prevalence of underlying chronic illness, ${ }^{43}$ most patients who are incarcerated do not have an advance directive or Physician's Orders for Life-Sustaining Treatment (POLST). ${ }^{44,45}$ There are multiple barriers to performing ACP. Restrictive prison policies and the attitudes of carceral staff may obstruct the process of $\mathrm{ACP}^{46}$ and there is evidence that physicians working in prisons and jails have limited knowledge of the role of ACP. ${ }^{47}$ Additionally, incarceration prevents patients from accessing the social supports (friends and family) that many non-incarcerated people rely on when making health care plans, similar to how visitor restrictions have impacted goals of care discussions during this pandemic. $^{48}$

If a patient admitted to the hospital from a prison or jail is found to lack decision-making capacity, it is crucial that clinicians follow state laws and ethical obligations when identifying a decision-making surrogate. ${ }^{44,48}$ Under most state laws, police officers, guards, or wardens do not have decision-making authority and state laws are not superseded by prison or jail policies. ${ }^{49}$ As hospital staff may feel intimidated by law enforcement officials, hospital policies should mention explicitly that health care agents and surrogate decision making are not to be limited by carceral policies - such policies are not an excuse for internists to violate their patient's right to treatment.

A hospital admission may give incarcerated patients an opportunity to discuss their goals of care in a safe environment with a physician who has experience with ACP and who is not part of the system that is incarcerating them. For sicker patients with COVID-19 being admitted to the hospital, this conversation takes on particular urgency and importance and requires it to be done thoughtfully and effectively. An incarcerated patient's wish to refuse treatment should be respected unless there is significant concern that the decision is being made for secondary gains such as a means of bargaining or protest $^{50}$, in which case the patient should be engaged in further patient-centered conversation.

\section{COMPASSIONATE RELEASE/MEDICAL PAROLE}

Physicians' expertise in caring for patients admitted from prisons and jails is highly variable, and some may lack familiarity with compassionate release/medical parole, i.e., the procedure for securing a terminally ill individual's release from jail or prison. While this is often a lengthy process due to demands of the justice system, it can be expedited ${ }^{51}$ and allows patients who are physically incapacitated to return to family for their remaining days. Compassionate release should be considered for any patient who has a prognosis of $<6$ months, irrespective of their COVID-19 status. Ongoing reevaluation of a patient's prognosis is important as the complications of COVID-19 infection may confer a limited prognosis on someone who otherwise may not have any life-limiting conditions. ${ }^{52}$ The Amend Group has provided resources to aid clinicians in pursuing compassionate release for their patients. The initial step involves contacting the prison or jail warden 
who may request a letter - a template of which is provided by the Amend Group - detailing the prognosis for incarcerated individuals. ${ }^{53}$ Ultimately, a patient may be discharged with home hospice or to a community hospice with the support afforded by any other patient in this setting. A critically ill incarcerated patient suffering from COVID-19 may not be stable enough for discharge and in this setting clinicians should facilitate a farewell visit with their loved ones. ${ }^{25}$

\section{RESEARCH AND VACCINATION}

The care of all hospitalized patients with COVID-19 continues to center on providing high-quality supportive care, with the consideration of adjunctive targeted treatments that have a wide range of proven efficacy and safety. ${ }^{28,54,55}$ Three of the twelve recommendations in the most recent iteration of the IDSA guideline on COVID-19 care recommend specific therapies only in the context of a clinical trial. ${ }^{29}$ Historically, incarcerated individuals have been exploited in research studies. ${ }^{56} \mathrm{In}$ an effort to prevent further abuse, additional planning, documentation, and IRB review is required in order to include incarcerated people in research. ${ }^{35}$ Some have questioned whether people who are imprisoned should have greater access to research, as this population may otherwise lack access to the latest and most promising medical therapies. ${ }^{57,58}$ The omission of incarcerated patients from the phase 3 COVID-19 vaccine trials has spurred debate over exactly this issue. ${ }^{59,60}$ While a detailed discussion relating to the inclusion of incarcerated participants in research is beyond the scope of this article, we should be aware of the restrictions on including people in prison or jails in research and make our best efforts to implement up to date best practices and hospital policies.

Now that vaccines for the prevention of COVID-19 have been authorized for emergency use by the Food and Drug Administration, the CDC Advisory Committee on Immunization Practices (ACIP) has identified corrections officers as non-healthcare essential frontline workers who should be vaccinated in phase $1 b^{61}$ The ACIP has not prioritized incarcerated persons for vaccination despite declarations from the National Academies of Sciences, Engineering, and Medicine and the American Medical Association that refusing to prioritize incarcerated persons for vaccination is irrational and unethical. ${ }^{62}$ Fortunately, despite these recommendations, some states have, nonetheless, prioritized this group, as documented by the COVID Prison Project. ${ }^{63}$

\section{CONCLUSION}

Incarcerated patients who are hospitalized with COVID-19 are physically impaired by shackling, vulnerable to poor communication, and stigmatization, and frequently have their privacy rights violated. This disempowers patients and places them at risk of poor clinical outcomes. In addition to being at particular risk of being infected, they have limited autonomy, and are
Table 2 Take-home Messages

\begin{tabular}{l}
\hline \hline Treat incarcerated patients with the dignity and respect due to any \\
patient; law enforcement presence or hospital policies should neither \\
interfere with providing respectful evidence-based care nor encourage \\
blaming the patient for their disease. \\
Destigmatize the diagnosis of COVID-19 in patients who are already \\
vulnerable to the stigma of being incarcerated by consciously \\
acknowledging the potential for implicit bias and taking steps to at a \\
minimum provide the standard of care you would any other patient. \\
Review your healthcare system's policies related to patients admitted \\
from prisons and jails so that you have a clear understanding about the \\
few restrictions on what you cannot tell your patients, i.e., specific \\
follow-up times and locations. \\
Commit to taking the extra time to ensure adequate communication and \\
understanding regarding the patients' clinical course and goals of care. \\
Work with risk management to improve security policies and remove \\
shackles unless custody or security staff has identified a legitimate \\
public safety risk. \\
Assure the equitable provision of routine standards of care: \\
- Play music or ask security to wear headphones during clinical \\
discussions to maintain privacy. \\
- Include family in communication if desired by the patient. \\
- Discuss advanced care planning and goals of care. \\
mecommend compassionate release if the patient's prognosis is $<6$ \\
months
\end{tabular}

already enmeshed in systems of oppression that separate them from their loved ones. Fundamental points to remember in caring for these patients in the COVID-19 era include minimizing the effect of security policies, such as shackles, on providing respectful care; acknowledging barriers to adequate communication and the need for a tactful approach to end-oflife discussions; taking a proactive stance to prognostication; and assisting with compassionate release (Table 2). It is crucial that the clinician advocate for incarcerated patients, and demand the equitable care that we seek for all our patients.

Corresponding Author: Alan P. Jacobsen, M.B., B.Ch., B.A.O.; Department of Medicine, Johns Hopkins University School of Medicine, Baltimore, MD, USA (e-mail: ajacob41@jhmi.edu).

\section{Declarations:}

Conflict of Interest: The authors declare that they do not have a conflict of interest.

\section{REFERENCES}

1. Bibbins-Domingo K. This Time Must Be Different: Disparities During the COVID-19 Pandemic. Ann Intern Med. 08 2020;173(3):233-234. doi:https://doi.org/10.7326/M20-2247

2. Cloud DH, Ahalt C, Augustine D, Sears D, Williams B. Medical Isolation and Solitary Confinement: Balancing Health and Humanity in US Jails and Prisons During COVID-19. J Gen Intern Med. 09 2020;35(9):27382742. doi:https://doi.org/10.1007/s11606-020-05968-y

3. Hawks L, Woolhandler S, McCormick D. COVID-19 in Prisons and Jails in the United States. JAMA Intern Med. Apr 2020;doi:https://doi.org/ 10. 1001/jamainternmed.2020.1856

4. Rubin R. The Challenge of Preventing COVID-19 Spread in Correctional Facilities. JAMA. Apr 2020;doi:https://doi.org/10.1001/jama.2020. 5427

5. Wallace M, Hagan L, Curran KG, et al. COVID-19 in Correctional and Detention Facilities - United States, February-April 2020. MMWR Morb Mortal Wkly Rep. May 2020;69(19):587-590. doi:https://doi.org/10. 15585/mmwr.mm6919e1

6. Alsan M, Yang CS. NCCHC-HU COVID-19 Survey of Correctional Facilities: Weekly Report. In: Care TNCoCH, editor. 2020. 
7. Jiménez MC, Cowger TL, Simon LE, Behn M, Cassarino N, Bassett MT. Epidemiology of COVID-19 Among Incarcerated Individuals and Staff in Massachusetts Jails and Prisons. JAMA Netw Open. 08 2020;3(8):e2018851. doi:https://doi.org/10.1001/jamanetworkopen. 2020.18851

8. Park K, Meagher T. The Marshall Project - A State-by-State Look at Coronavirus in Prisons. Accessed July 4th 2020, https://www. themarshallproject.org/2020/05/01/a-state-by-state-look-at-coronavirus-in-prisons

9. Medicine JHUa. Coronavirus resource center - Mortality Analyses. Accessed July 4th 2020, https://coronavirus.jhu.edu/data/mortality

10. Saloner B, Parish K, Ward JA, DiLaura G, Dolovich S. COVID-19 Cases and Deaths in Federal and State Prisons. JAMA. Jul 2020;doi:https:// doi.org/10.1001/jama.2020.12528

11. Altibi AM, Pallavi B, Liaqat $\mathbf{H}$, et al. Characteristics and comparative clinical outcomes of prisoner versus non-prisoner populations hospitalized with COVID-19. Sci Rep. Mar 2021;11(1):6488. doi:https://doi.org/ 10.1038/s41598-021-85916-w

12. Price-Haywood EG, Burton J, Fort D, Seoane L. Hospitalization and Mortality among Black Patients and White Patients with Covid-19. N Engl $J$ Med. 06 2020;382(26):2534-2543. doi:https://doi.org/10.1056/ NEJMsa2011686

13. Boyd R, Lindo E, Weeks L, Mc Lemore M. On Racism: A New Standard For Publishing On Racial Health Inequities. Health Affairs Blog; 2020.

14. Bureau of Justice Statistics. What is the difference between jails and prisons?

15. Koester L, Brenner JM, Goulette A, Wojcik SM, Grant W. Inmate Health Care Provided in an Emergency Department. $J$ Correct Health Care. Apr 2017;23(2):157-161. doi:https://doi.org/10.1177/ 1078345817699595

16. Akiyama MJ, Spaulding AC, Rich JD. Flattening the Curve for Incarcerated Populations - Covid-19 in Jails and Prisons. N Engl J Med. Apr 2020;doi:https://doi.org/10.1056/NEJMp2005687

17. Simpson PL, Butler TG. Covid-19, prison crowding, and release policies. BMJ. 04 2020;369:m1551. doi:https://doi.org/10.1136/bmj.m1551

18. Barr WP. Memorandum for Director of Bureau Prisons. The Attorney General, 2020.

19. National Academies of Sciences, Engineering, and Medicine. Decarcerating Correctional Facilities during COVID-19: Advancing Health, Equity, and Safety. The National Academies Press; 2020:134.

20. Berwick DM, Gale L, Barksdale F, Hauptman M. Protecting Incarcerated People In The Face Of COVID-19: A Health And Human Rights Perspective. Health Affairs Blog; 2020.

21. Mitka M. Aging prisoners stressing health care system. JAMA. Jul 2004;292(4):423-4. doi:https://doi.org/10.1001/jama.292.4.423

22. Maruschak LM, Berzofsky M, Unangst J. Medical Problems of State and Federal Prisoners and Jail Inmates, 2011-12. 2015.

23. Howell BA, Long JB, Edelman EJ, et al. Incarceration History and Uncontrolled Blood Pressure in a Multi-Site Cohort. J Gen Intern Med. 12 2016;31(12):1496-1502. doi:https://doi.org/10.1007/s11606-0163857-1

24. Haber LA, Erickson HP, Ranji SR, Ortiz GM, Pratt LA. Acute Care for Patients Who Are Incarcerated: A Review. JAMA Intern Med. Sep 2019; doi:https://doi.org/10.1001/jamainternmed.2019.3881

25. Rorvig L, Williams B. Providing Ethical and Humane Care to Hospitalized, Incarcerated Patients With COVID-19. Am J Hosp Palliat Care. Feb 2021:1049909121994313. doi:https://doi.org/10.1177/ 1049909121994313

26. Rovig L, Williams B. Providing Acute Care For Seriously Ill Incarcerated Patients. In: AMEND, editor. CA, USA2020. p. 1-5.

27. National Commission on Correctional Health Care. 2018 Standards for Health Services in Prisons. Chicago, Illinois. 2018.

28. Centers for Disease Control and Prevention (CDC). Interim Clinical Guidance for Management of Patients with Confirmed Coronavirus Disease (COVID-19). 2020.

29. Infectious Disease Society of America. Strengthening the Response to COVID-19 in Correctional Facilities. 2020

30. Sears D, Ahalt C, Augustine D, Williams B. Occupational Health: A Key to the Control of COVID-19 in Correctional Facilities. Ann Intern Med. Jul 2020;doi:https://doi.org/10.7326/M20-4543

31. Dreyer NJ, Terry AT. American College of Emergency Physicians Covid19 Field Guide: Incarcerated Patients USA2020.

32. Society of General Internal Medicine. Ensuring equity amid the COVID19 pandemic: A statement to members. USA2020.

33. Bednar AL. HIPAA's Impact on Prisoners' Rights to Healthcare. Houston: Houston Journal of Health Law and Policy; 2003.
34. Hill P, Baker D. Care of Patient in Custody (Prisoner/Inmate). Baltimore, MD, USA: Johns Hopkins Hospital - Interdisciplinary Clinical Practice Manual Patient Care; 2018. p. 1-8.

35. Abdoler E, Malani PN, Malani AN. Policy Considerations for Persons Who Are Incarcerated and Hospitalized with Coronavirus Disease 2019. JAMA Health Forum. 2020;1(9):e201089-e201089. doi:https://doi.org/ 10.1001/jamahealthforum.2020.1089

36. DiTomas M, Bick J, Williams B. Shackled at the End of Life: We Can Do Better. Am J Bioeth. 07 2019;19(7):61-63. doi:https://doi.org/10.1080/ 15265161.2019.1618957

37. Williams B. Expert Report of Brie Williams, M.D., M.S. Parsons v Ryan, No 2: 12-cv-00601-NVW (MEA) (D Ariz). San Francisco, CA, USA2013. p. $1-20$.

38. Edelson DP, Sasson C, Chan PS, et al. Interim Guidance for Basic and Advanced Life Support in Adults, Children, and Neonates With Suspected or Confirmed COVID-19: From the Emergency Cardiovascular Care Committee and Get With The Guidelines-Resuscitation Adult and Pediatric Task Forces of the American Heart Association. Circulation. 06 2020;141(25):e933-e943. doi:https://doi.org/10.1161/ CIRCULATIONAHA. 120.047463

39. Rathore FA, Ilyas A. Post-Intensive Care Syndrome and COVID-19: Crisis After a Crisis? Heart Lung Circ. Sep 2020;doi:https://doi.org/10. 1016/j.hlc.2020.08.011

40. Health NIfR. 2019 Report: Gaining Ground: Proactive Reproductive Health and Rights Legislation in the States. New York, NY, USA2020. p. $1-64$.

41. Colwell J. Caring for Prisoners. In: Hospitalist A, editor. 2017.

42. Haigler KO, Harlow C, O'Connor P, Campbell A. Literacy Behind Prison Walls. National Center for Educational Statistics, Office of Educational Research and Improvement, US Dept of Education, Washington DC 1994. p. 187.

43. Williams BA, Goodwin JS, Baillargeon J, Ahalt C, Walter LC. Addressing the aging crisis in U.S. criminal justice health care. $J$ Am Geriatr Soc. Jun 2012;60(6): 1150-6. doi:https://doi.org/10.1111/j.15325415.2012.03962.x

44. Tobey M, Simon L. Who Should Make Decisions for Unrepresented Patients Who Are Incarcerated? AMA J Ethics. 07 2019;21(7):E617-624. doi:https://doi.org/10.1001/amajethics.2019.617

45. Linder JF, Meyers FJ. Palliative care for prison inmates: "don't let me die in prison”. JAMA. Aug 2007;298(8):894-901. doi:https://doi.org/10. 1001/jama.298.8.894

46. Macleod A, Nair D, Ilbahar E, Sellars M, Nolte L. Identifying barriers and facilitators to implementing advance care planning in prisons: a rapid literature review. Health Justice. Sep 2020;8(1):22. doi:https://doi. org/10.1186/s40352-020-00123-5

47. Ekaireb R, Ahalt C, Sudore R, Metzger L, Williams B. "We Take Care of Patients, but We Don't Advocate for Them": Advance Care Planning in Prison or Jail. J Am Geriatr Soc. 12 2018;66(12):2382-2388. doi:https:// doi.org/10.1111/jgs.15624

48. Scarlet S, DeMartino ES, Siegler M. Surrogate Decision Making for Incarcerated Patients. JAMA Intern Med. 07 2019;179(7):861-862. doi:https://doi.org/10.1001/jamainternmed.2019.1386

49. Dober G. Beyond Estelle: Medical Rights for Incarcerated Patients. United States of America: Prison Legal News; 2019.

50. Peteet T, Tobey M. How Should a Health Care Professional Respond to an Incarcerated Patient's Request for a Particular Treatment? AMA J Ethics. Sep 2017;19(9):894-902. doi:https://doi.org/10.1001/ journalofethics.2017.19.9.ecas3-1709

51. Jacobsen AP, Epstein JA. Dying Without Covid-19: End-of-life Care for an Uninfected Incarcerated Patient. Mayo Clinic Proceedings. 2020;doi:https://doi.org/10.1016/j.mayocp.2020.07.022

52. Amend. Requesting Compassionate (Early) Release/Parole During COVID-19. Accessed October 31st, 2020, https://amend.us/ requesting-compassionate-early-release-parole-during-covid-19/

53. Amend, University of California, San Francisco. COVID-19 in Your Correctional Facility: Answers, Advice and Actions. 15:02:55, https:// amend.us/covid/

54. World Health Organisation. Clinical management of Covid-19. 2020.

55. Bhimraj A, Morgan RL, Shumaker AH, et al. Infectious Diseases Society of America Guidelines on the Treatment and Management of Patients with COVID-19. Clin Infect Dis. Apr 2020;doi:https://doi.org/10.1093/ cid/ciaa478

56. Hornblum AM. They were cheap and available: prisoners as research subjects in twentieth century America. BMJ. Nov 1997;315(7120):143741. doi:https://doi.org/10.1136/bmj.315.7120.1437 
57. Christopher PP, Stein MD, Johnson JE, et al. Exploitation of Prisoners in Clinical Research: Perceptions of Study Participants. IRB. 2016 JanFeb 2016;38(1):7-12.

58. Ahalt C, Haney C, Kinner S, Williams B. Balancing the Rights to Protection and Participation: A Call for Expanded Access to Ethically Conducted Correctional Health Research. J Gen Intern Med. 05 2018;33(5):764-768. doi:https://doi.org/10.1007/s11606-018-4318-9

59. Wang EA, Zenilman J, Brinkley-Rubinstein L. Ethical Considerations for COVID-19 Vaccine Trials in Correctional Facilities. JAMA. Sep 2020;324(11):1031-1032. doi:https://doi.org/10.1001/jama.2020. 15589

60. Strassle C, Jardas E, Ochoa J, et al. Covid-19 Vaccine Trials and Incarcerated People - The Ethics of Inclusion. $N$ Engl $\mathrm{J}$ Med Oct 2020;doi:https://doi.org/10.1056/NEJMp2025955
61. Dooling K, Marin M, Wallace $\mathbf{M}$, et al. The Advisory Committee on Immunization Practices' Updated Interim Recommendation for Allocation of COVID-19 Vaccine - United States, December 2020. MMWR Morb Mortal Wkly Rep. Jan 202 1;69(5152):1657-1660. doi:https://doi.org/10. 15585/mmwr.mm695152e2

62. Barsky BA, Reinhart E, Farmer P, Keshavjee S. Vaccination plus Decarceration - Stopping Covid-19 in Jails and Prisons. N Engl J Med. Mar 2021;doi:https://doi.org/ 10.1056/NEJMp2100609

63. Brinkley-Rubinstein L, Nowotny KM. The COVID Prison Project. USA2021.

Publisher's Note: Springer Nature remains neutral with regard to jurisdictional claims in published maps and institutional affiliations. 